\title{
Influence of fat replacement by inulin on rheological properties, kinetics of rennet milk coagulation, and syneresis of milk gels
}

\author{
O. Arango, ${ }^{*} \dagger$ A. J. Trujillo, ${ }^{*}$ and M. Castillo*1 \\ ${ }^{*}$ Centre Especial de Recerca Planta de Tecnologia dels Aliments (CERPTA), Departament de Ciència Animal i dels Aliments, \\ Facultat de Veterinària, Universitat Autònoma de Barcelona, 08193-Bellaterra, Spain \\ †Universidad de Nariño, Facultad de Ingeniería Agroindustrial, Ciudad Universitaria Torobajo, Pasto, Nariño 520002, Colombia
}

\section{ABSTRACT}

The objective of this study was to evaluate the effect of inulin as a fat replacer on the rheological properties, coagulation kinetics, and syneresis of milk gels. A randomized factorial design, replicated 3 times, with 3 inulin concentrations (0,3, and 6\%), 2 levels of fat $(<0.2$ and $1.5 \%)$, and 3 coagulation temperatures (27, 32 , and $37^{\circ} \mathrm{C}$ ) was used. The coagulation process was monitored using near-infrared spectrometry, small amplitude oscillatory rheometry, and visual coagulation indexes. The syneresis was evaluated by volumetric methods. Inulin addition increased the rates of aggregation and curd firming reactions in the casein gels. The observed effect, which was more evident on the aggregation reaction, depended on the concentration of inulin and the coagulation temperature. Addition of $6 \%$ inulin reduced the clotting time by approximately $26 \%$ and the time at which the gel reached a storage modulus equal to $30 \mathrm{~Pa}$ by approximately $36 \%$. The optical parameter $R_{\text {max }}^{\prime}$, defined as the maximum value of change in light backscatter profile/change in time (where $R^{\prime}=\mathrm{d} R / \mathrm{d} t$ ), was used to calculate an approximation of the temperature coefficients $\left(Q_{10}\right)$ for milk coagulation. Increasing fat concentration induced a consistent increase in all the optical, rheological, and visual parameters studied, although the observed trend was not statistically significant. The addition of inulin at a level of $6 \%$ produced a reduction in syneresis and increased the curd yield by approximately $30 \%$. It was concluded that the addition of inulin affects the kinetics of milk coagulation and the cutting time and, therefore, the use of inline sensors such as near-infrared spectrometry may be necessary for optimal process control.

Key words: inulin, milk coagulation properties, syneresis, near-infrared sensor

Received May 23, 2012.

Accepted December 27, 2012

${ }^{1}$ Corresponding author: manuel.castillo@uab.es

\section{INTRODUCTION}

During the last few years, the concern and awareness of consumers about the relationship between diet and health has increased, which has led to a tendency to reduce the consumption of high-fat foods. Many types of cheese are a significant source of dietary fat, but reducing its content represents a technological challenge, as the lipid fraction alters the rheological properties and, therefore, the texture, organoleptic properties, and the functionality of the product (Zhou and Mulvaney, 1998).

Inulin is a nondigestible carbohydrate of special interest to the dairy industry as a result, among other reasons, of its functional properties. An overview of the applications of inulin in various foods has been made by Kalyani Nair et al. (2010). Inulin has a neutral taste, is colorless, and has minimal influence on the sensory characteristics of a product, so it could be considered as an invisible way of incorporating fiber to foods. The high solubility of this functional ingredient compared with classical fibers makes it relevant to fortify dairy products such as milk drinks, yogurt, cheese, and desserts. Inulin is also found to improve the stability of foams and emulsions such as in aerated desserts, ice creams, table spreads, and sauces (Franck, 2002; Kip et al., 2006; Roberfroid, 2007).

Inulin ingestion provides the benefits inherent not only to its condition as a dietetic fiber (e.g., reducing blood cholesterol and lipid levels, intestinal traffic control, and increasing calcium absorption), but also those derived from its prebiotic nature, related mainly to stimulation of growth of bifidobacteria and regulation of intestinal flora in the colon (Roberfroid and Slavin, 2000).

So far, studies exist on the effect of different biopolymers and sources of dietary fiber such as $\kappa$-carrageenan, guar gum, xanthan gum, pectin, gelatin, and inulin on the rheological properties and the microstructure of casein gels, which allows a decline in the gelation times (Fagan et al., 2006; Tan et al., 2007). In yogurt elaboration, it has been found that inulin addition as a fat replacer allows rheological behavior very similar to that 
of the control samples with fat and the improvement of the sensory characteristics of the product (Kip et al., 2006; Paseephol et al., 2008; Modzelewska-Kapituła and Kłębukowska, 2009).

Hennelly et al. (2006) studied fat replacement by inulin in matrices of cheese imitation, and they found that up to $63 \%$ of the fat can be replaced by inulin without affecting the melting characteristics of cheese. Inulin has also been successfully used as a partial replacer for fat in Mozzarella cheese (Pagliarini and Beatrice, 1994), and when it was added to fresh cheeses at levels of up to $100 \mathrm{~g} / \mathrm{kg}$, it did not affect the aroma of the product (Gijs et al., 2000).

The optical sensor technology has been tested as a useful tool to control milk coagulation. In particular, the fiber optic light backscatter near-infrared (NIR) sensor CoAguLite (Reflectronics Inc., Lexington, KY) is an inline sensor that has been well documented to monitor milk coagulation and predict gelation and cutting time (Castillo, 2001).

Although several studies exist that evaluate the effect of inulin on the rheological and sensory characteristics of different dairy products, still little information exists about the influence of inulin on various parameters of interest in cheese processing, such as gelation and cutting time, the kinetics of the syneresis process, and curd yield. For this reason, the objective of this study was to assess the effect of fat replacement by inulin on rheological properties, and the kinetics of the coagulation and syneresis processes in milk gels.

\section{MATERIALS AND METHODS}

\section{Experimental Design}

An experimental design with 3 factors: coagulation temperature $\left(27,32\right.$, and $\left.37^{\circ} \mathrm{C}\right)$, inulin concentration $(0,3$, and $6 \%)$, and fat concentration (0.2 and $1.5 \%)$ was used in this study. The experiment was replicated 3 times, performing a total of 54 trials. Tests were carried out in random order to minimize systematic sources of error. The $\mathrm{pH}$ as well as the protein, calcium chloride, and enzyme concentrations were set at a constant value to reduce variability and better observe the effect of the main factors (Table 1). The inulin levels were chosen according to the European regulation (European Parliament, 2006), which claims that inulin as a source of dietary fiber should be present in the food in quantities greater than or equal to $3 \%$.

Coagulation was monitored using visual, optical (NIR), and rheological parameters. The whey separation kinetics was determined by means of volumetric methods. The different types of tests carried out, including the syneresis measurements, were developed in parallel by taking as time zero the moment in which the enzyme was added to the milk.

\section{Enzyme and Inulin}

Recombinant chymosin 100\% [CHY-MAX extra; EC 3.4.23.4, isozyme B, 600 international milk clotting units (IMCU)/mL], supplied by Chr. Hansen Inc. (Barcelona, Spain), was used to induce milk coagulation. The enzyme was stored refrigerated at $4^{\circ} \mathrm{C}$ and added at a concentration of $100 \mu \mathrm{L} / \mathrm{kg}$ of milk at the beginning of the trials.

The inulin used was Frutafit, supplied by Brenntag Química S.A. (Barcelona, Spain). This type of inulin that is extracted from chicory roots has an average degree of polymerization $\geq 23$ and an amorphous structure (Glibowski and Pikus, 2011).

\section{Milk Reconstitution}

To reduce the variability inherent in the composition of fresh milk, low-heat skim milk powder (Chr. Hansen Inc.) was used as the main source of protein for clotting, whereas cream extracted from fresh milk obtained from a local farm (S.A.T. Can Badó Santa Agnés, Barcelona, Spain) was used as the source of fat. Once it was extracted, the cream was heat treated at $63^{\circ} \mathrm{C}$ for $30 \mathrm{~min}$ in a water bath and immediately stored at $4^{\circ} \mathrm{C}$ until it was used. The contents of protein and fat of powdered milk and cream were determined through Dumas (IDF, 2002) and Gerber (AOAC International, 2000) methods, respectively.

Mass balance was carried out to adjust the proportions of protein, fat, and inulin according to the experimental design. The corresponding amount of powdered milk was dissolved in distilled water at a temperature of approximately $43^{\circ} \mathrm{C}$ for $1 \mathrm{~h}$ by using a heating plate with stirring. After the reconstitution process, a constant proportion of $\mathrm{CaCl}_{2}$ of $0.156 \mathrm{~g} / \mathrm{kg}$ was added. Cream was tempered at $30^{\circ} \mathrm{C}$ and the required quantity was agitated and weighed in a beaker. The aliquot of

Table 1. Experimental factors and their levels used in the experimental design

\begin{tabular}{lcrc}
\hline & \multicolumn{3}{c}{ Level } \\
\cline { 2 - 4 } Factor & 1 & 2 & 3 \\
\hline Temperature $\left({ }^{\circ} \mathrm{C}\right)$ & 27 & 32 & 37 \\
Inulin concentration $(\%)$ & 0 & 3 & 6 \\
Fat concentration $(\%)$ & $<0.2$ & & 1.5 \\
Milk protein concentration $(\%)$ & 3.4 & & \\
Enzyme concentration $(\mu \mathrm{L} / \mathrm{kg})$ & 100 & 0.156 & \\
CaCl & concentration $(\mathrm{g} / \mathrm{kg})$ & 6.70 & \\
pH of milk & & \\
\hline
\end{tabular}


cream contained in a $50-\mathrm{mL}$ beaker was added to the reconstituted milk and then the beaker was rinsed with approximately $25 \mathrm{~mL}$ of milk to collect the remaining cream and minimize the experimental error. The average protein content and $\mathrm{pH}$ value of the reconstituted milk samples were $3.33 \pm 0.04$ and $6.66 \pm 0.01 \%$, respectively, whereas the average values corresponding to the 2 levels of fat used in the experimental design were $0.14 \pm 0.02$ and $1.56 \pm 0.06 \%$, respectively.

\section{Testing Procedures}

The 54 tests, which constituted the experimental design, were performed within $6 \mathrm{wk}$, with an average of 9 trials per week and 3 per day. Each test used 570 $\mathrm{mL}$ of reconstituted milk with the corresponding levels of fat, protein, and inulin. This reconstituted milk was tempered to the target temperature using a water bath. The beaker containing the milk was covered with Parafilm to avoid evaporation and the corresponding surface cooling of the sample. Figure 1 presents a scheme of the distribution of samples in the trials.

Once the milk reached the target temperature, the enzyme was added and stirred thoroughly with a spatula for $20 \mathrm{~s}$. Immediately, 2 aliquots of approximately $80 \mathrm{~mL}$ were placed in the optical sensor vessels and the NIR light backscatter monitoring software (Reflectronics Inc.) was started. Another aliquot of approximately $40 \mathrm{~mL}$ was placed in the rheometer and the respective data acquisition software was launched. To follow up the visual milk coagulation process control indices clotting time $\left(\boldsymbol{t}_{\text {clot }}\right)$, and cutting time $\left(\boldsymbol{t}_{\text {cut }}\right)$, another aliquot of $160 \mathrm{~mL}$ of milk with enzyme was rapidly placed in a 250-mL beaker, which remained within the water bath covered with Parafilm. Finally, 3 aliquots of $70 \mathrm{~mL}$ each

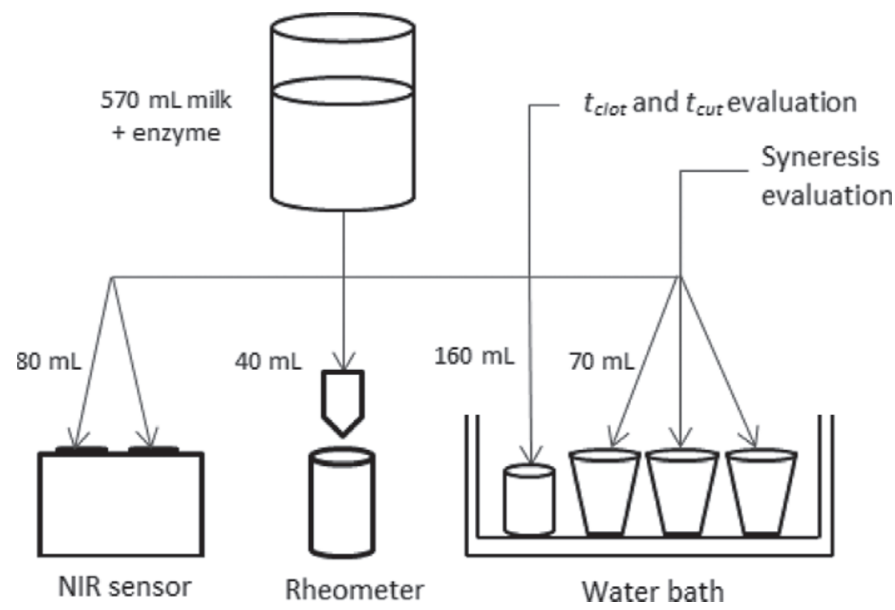

Figure 1. Distribution of the sample in the tests. $t_{\text {clot }}=$ clotting time; $t_{\text {cut }}=$ cutting time. were taken and placed in plastic cups, which were also maintained in the water bath at the temperature of the test to perform the cutting of the curd and evaluate the syneresis once the gel reached $30 \mathrm{~Pa}$ of hardness [elastic modulus or storage modulus $\left(\boldsymbol{G}^{\prime}\right)=30 \mathrm{~Pa}$, measured by the rheometer]. The entire distribution of samples shown in Figure 1 was carried out in an average time of approximately $2 \mathrm{~min}$, taking care to minimize the temperature variations at any time.

\section{Visual Parameters Determination}

The method used to evaluate the $t_{\text {clot }}$ was an adaptation of the $t_{\text {clot }}$ proposed by N. J. Berridge (IDF, 2007). We used a spatula, which was repeatedly introduced into the gel until the appearance of small flocks of casein was visually perceptible on the surface of the spatula. Cutting time was determined according to the procedure described by Castillo et al. (2000), by using a glass rod with rounded edges of $0.3-\mathrm{cm}$ diameter and $15 \mathrm{~cm}$ long. It was introduced repeatedly in the gel to the bottom vessel until it would remain vertical for $3 \mathrm{~s}$ without being sustained. From this moment, to confirm the $t_{\text {cut }}$, a spatula was used to separate the gel from the walls of the beaker, until the separation was completely clean, and the gel offered elastic resistance without being broken when forced toward the center of the beaker with the spatula.

\section{Syneresis Evaluation}

In each trial, the syneresis was evaluated in triplicate using 3 plastic commercial molds for fresh cheese-whey separation (Figure 2). The basket fit perfectly within the external container and it was fixed in a limit that was located $15 \mathrm{~mm}$ from the surface, leaving a separation of approximately $20 \mathrm{~mm}$ between the bases of both containers. This double-basket configuration was used to contain the curd in the mentioned $20-\mathrm{mm}$ space to prevent its exit while the whey was drained.

Three aliquots of $70 \mathrm{~mL}$ of milk with enzyme were deposited in each of the internal containers of the molds, which were kept at the temperature of the trial in a water bath. When the value of $G^{\prime}$ in the sample reached $30 \mathrm{~Pa}, 10$ cuts we made in the curd by using a cutter to get square base prisms with edges of approximately $10 \mathrm{~mm}$. The time at which the cutting of the curd was completed was established as the beginning of the whey separation time $(t=0 \mathrm{~min})$.

When making the first measurement, the container with the curd was removed from the water bath, inclined at an angle of $45^{\circ}$, and left to drain the whey for $30 \mathrm{~s}$ by collecting the liquid (whey) in a beaker placed on a balance. Immediately after the measurement, the 


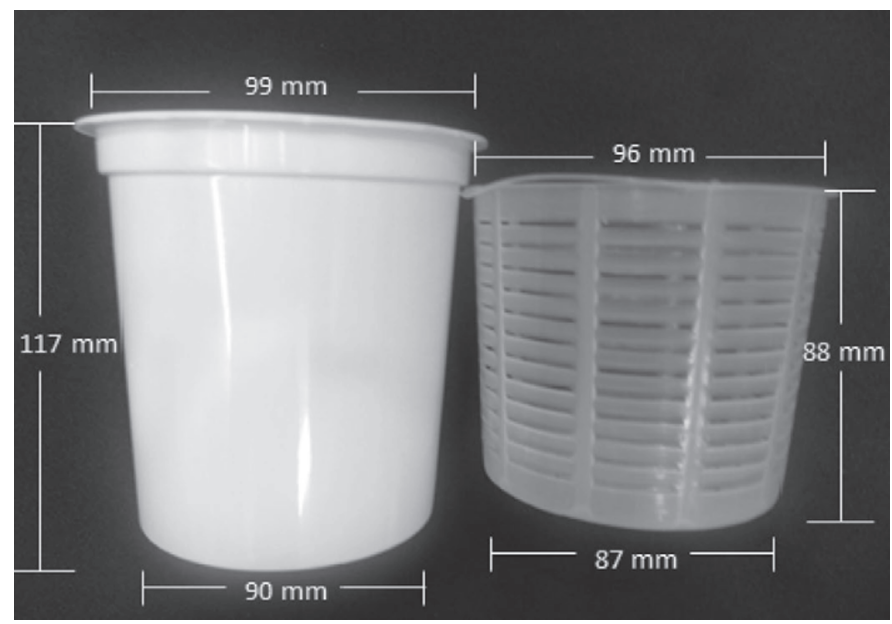

Figure 2. Apparatus used for syneresis evaluation.

container was again placed in the thermostatic bath until the next measurement. The calculations were made successively every $5 \mathrm{~min}$ until time $t=40 \mathrm{~min}$. From this moment, the calculations were carried out every 10 min until $t=90 \mathrm{~min}$ and, subsequently, 2 more measurements were made every $30 \mathrm{~min}$ to complete a whey-draining period of $150 \mathrm{~min}$.

Because it has been widely confirmed in previous studies that the whey expulsion from the rennet-induced milk gels follows first-order kinetics (Marshall, 1982; Peri et al., 1985; Castillo et al., 2006b), the following first-order equation was fitted to the data:

$$
W=W_{\infty}\left(1-e^{-k t}\right),
$$

where $W$ was the weight of the whey (g) at time $t$ (min), $W_{\infty}$ was the mass of whey drained $(\mathrm{g})$ at infinite time, and $k$ was the kinetic rate constant $\left(\min ^{-1}\right)$ for the syneresis process. The total accumulated whey mass (g), which was drained over 150 min after the cutting of the curd, was defined as $\boldsymbol{W}_{\boldsymbol{A}}$. The curd yield (CY) was calculated as the percentage between the final weight of the curd after $150 \mathrm{~min}$ of drainage and the initial weight of the milk.

\section{Determination of NIR Optical Dispersion Parameters}

The equipment used to determine the NIR light backscatter profile at $880 \mathrm{~nm}$ during milk coagulation was designed at the University of Kentucky (Lexington). A detailed description of the equipment was presented in the work of Tabayehnejad et al. (2011). The device has 2 vats of $98-\mathrm{mL}$ capacity to monitor coagulation in 2 samples simultaneously. Each vat is equipped with the instrumentation needed to measure the light scattering, temperature, and $\mathrm{pH}$ during clotting. The optical data generated in the vats were collected at intervals of $6 \mathrm{~s}$. The light backscatter profile (Figure 3) was calculated by dividing the voltage output from the detector by the average of the first 10 voltage data points collected after the enzyme addition, according to the procedure described by Castillo et al. (2000).

As described by Castillo et al. (2006a), an algorithm was used to calculate the first $\left(\boldsymbol{R}^{\prime}\right)$ and second $\left(\boldsymbol{R}^{\prime \prime}\right)$ derivatives of the light backscatter profile $(\boldsymbol{R})$. Several optical time parameters (min) were defined by the maxima and minima of the derivatives, as shown in Figure 3. The elapsed times since enzyme addition to the first maximum of the first and second derivatives were defined as $t_{\max }$ and $t_{2 \max }$, respectively, whereas the times to the second maximum of the first and second derivatives were defined as $t_{\max 2}$ and $t_{2 \max 2}$, respectively. The times to the first and second minima of the second derivative were defined as $t_{2 \min }$ and $t_{2 \min 2}$, respectively. Two complementary optical parameters were defined as $\boldsymbol{R}_{\max }$ and $\boldsymbol{R}_{\max 2}$, which corresponded to the values of $R$ at $t_{\max }$ and $t_{\max 2}$, respectively.

\section{Rheological Parameters Determination}

The milk coagulation process was monitored through small amplitude oscillatory rheology (SAOR) using a Thermo Haake rheometer RS1 (Thermo Haake GmbH, Karlsruhe, Germany) equipped with a concentric-cylinders sensor (Z34). The tests were done by applying a deformation of $3 \%$, which is within the region of linear viscoelasticity for rennet milk gels (Zoon et al. 1988) and a frequency of $1 \mathrm{~Hz}$. One aliquot of $40 \mathrm{~mL}$ of milk with enzyme, which was tempered at the temperature of the test, was deposited in the cylinder of the rheometer, and a thin mineral oil layer was added to the surface of the sample to avoid losses by evaporation and surface cooling. The parameters identified were the $G^{\prime}$, the viscous modulus or loss modulus $\left(\boldsymbol{G}^{\prime \prime}\right)$, and $\tan \delta$ $\left(\tan \delta=G^{\prime \prime} / G^{\prime}\right)$. Gelation time $\left(\boldsymbol{t}_{G^{\prime \prime}}\right)$ was defined as the time when the gels had a $G^{\prime}=1 \mathrm{~Pa}$. Other identified parameters were $t_{G^{\prime \prime} 30}$ and $t_{G^{\prime \prime} 60}$, corresponding to the times when $G^{\prime}$ reached values of 30 and $60 \mathrm{~Pa}$, respectively; and $t_{F 30}$ and $t_{F 60}$, which referred to the elapsed times between $G^{\prime}=1 \mathrm{~Pa}$ and $G^{\prime}=30 \mathrm{~Pa}$ and $60 \mathrm{~Pa}$, respectively. In the same way, the parameters $\tan \delta_{30}$ and $\tan \delta_{60}$ referred to the value of $\tan \delta$ when $G^{\prime}=30$ $\mathrm{Pa}$ and $G^{\prime}=60 \mathrm{~Pa}$, respectively.

\section{Statistical Analysis}

All data were processed and analyzed using SAS software (SAS version 9, 2004; SAS Institute Inc., Cary, NC). Pearson correlation coefficients were determined with PROC CORR, whereas ANOVA was performed 


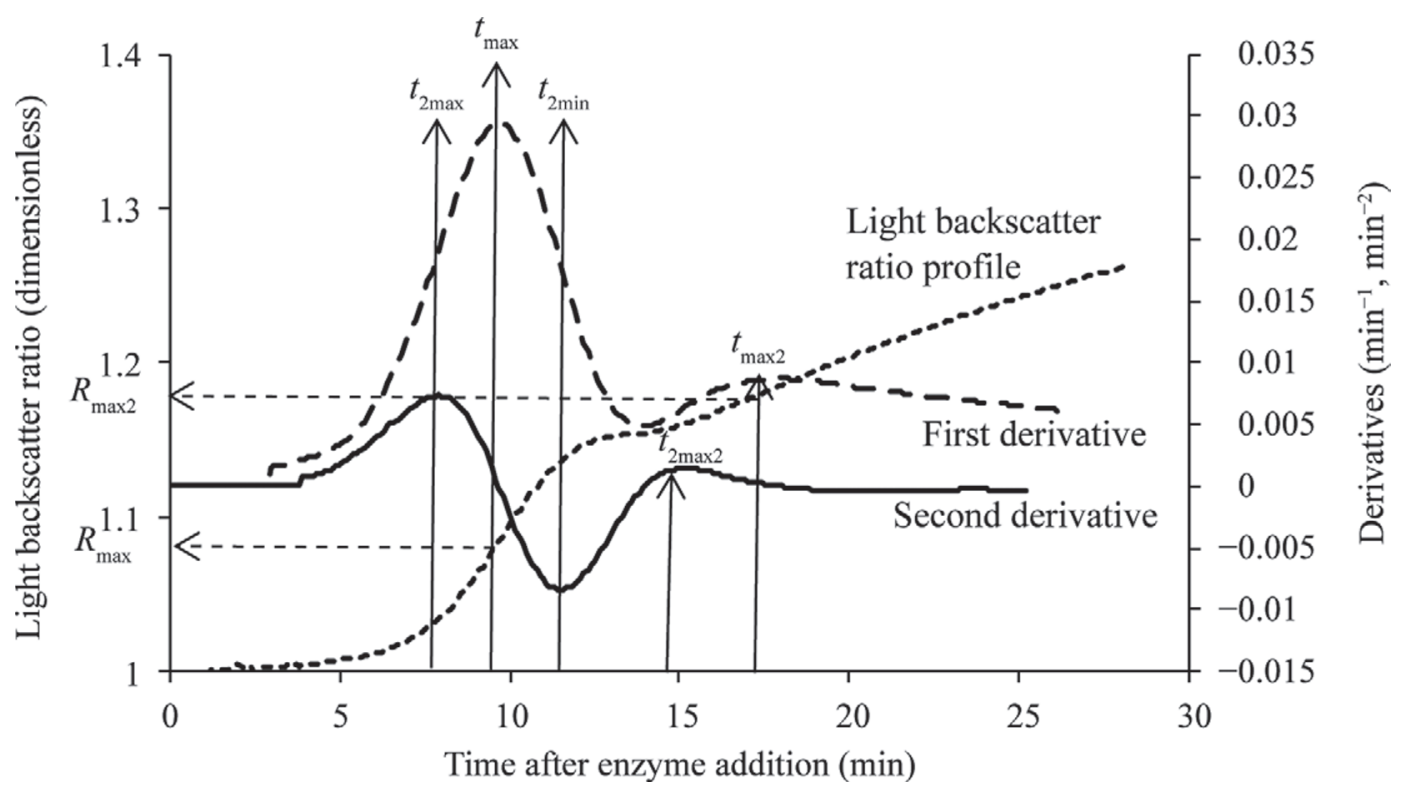

Figure 3. Light backscatter profile and its first and second derivative versus time. Data were obtained from the mean of 3 replications at $27^{\circ} \mathrm{C}$ temperature, $6 \%$ inulin, and $0.2 \%$ fat. $t_{\max }$ and $t_{2 \max }=$ elapsed times since enzyme addition to the first maximum of the first and second derivatives, respectively; $t_{\max 2}$ and $t_{2 \max 2}=$ times to the second maximum of the first and second derivatives, respectively; $t_{2 \min }=$ time to the first minimum of the second derivative. $R_{\max }$ and $R_{\max 2}=$ the values of $R$ at $t_{\max }$ and $t_{\max 2}$, respectively.

using PROC GLM. The statistical models included the experimental design factors as main effects, as well as the most important interactions between the studied factors. The random effect exerted on the studied parameters by various not-fixed variables was considered by the inclusion of covariables in the model. In particular, the main selected effects were the temperature of the test $(\boldsymbol{T})$, the percentage of inulin $(\boldsymbol{I})$, the concentration of fat in milk $(\boldsymbol{F})$, and the replication. The main interactions included were temperature-inulin $(T \times I)$, temperature-fat $(T \times F)$, and inulin-fat $(I \times F)$, whereas the protein:fat ratio and $\mathrm{pH}$ were introduced as covariables. After a preliminary analysis of the data, all those interactions and covariables that did not contribute significantly to the variability of the data were eliminated. Least squares means and significance of treatments were calculated using type IV sum of squares. Least squares means values were considered to be statistically different when $P<0.05$.

\section{RESULTS AND DISCUSSION}

The reconstituted milk coagulation process was monitored at the same time through optical and rheological methods and by visual observation, and an ANOVA was conducted to determine the main sources of variation in the dependent variables. Table 2 shows the ANOVA for the dependent variables studied.
Significant temperature effects were observed $(P<$ 0.05 ) for all the evaluated dependent variables, with the exception of $W_{\infty}$, whereas the effect of inulin concentration was found to be significant for all variables except $W_{\infty}, W_{A}, t_{2 \max 2}$ and $t_{2 \min 2}, t_{F 60}$, and $\tan \delta_{30}$ and $\tan \delta_{60}$. Fat concentration only had significant effect on $t_{2 \max 2}$. The effect of the interaction $T \times I$ was significant on the variables $t_{\mathrm{clot}}, t_{\mathrm{cut}}, t_{\max }, t_{\max 2}, t_{G^{\prime} 1}, t_{G^{\prime} 30}, t_{F 30}$, and $\tan \delta_{30}$ and $\tan \delta_{60}$. The $T \times F$ interaction only had significant effect on the variable $\tan \delta_{60}$. Significant effects of $\mathrm{pH}$ were observed on $k, t_{G^{\prime} 1}, t_{G^{\prime} 30}, t_{F 30}$. Regarding the replication, it remained in the model due to significant effects on the variables $k, t_{\text {cut }}, t_{2 \min }, t_{G^{\prime \prime}}, t_{G^{\prime} 30}$, and $t_{F 30}$, which could be explained by the fact of having used cream extracted from different milk batches in each replication.

\section{Effect of Experimental Factors on Coagulation and Gel Rheological Properties}

Inulin Concentration Effect. To explain the effect of the addition of inulin on coagulation kinetics and the rheological characteristics of milk gels, it must be first understood the way in which inulin can form gels and factors affecting its properties. Glibowski and Pikus (2011) and Kim et al. (2001) observed that gel formation from inulin dissolutions in water and the rheological properties of those gels depended on the 
Table 2. Analysis of variance and $F$-statistics for dependent variables ${ }^{1}$

\begin{tabular}{|c|c|c|c|c|c|c|c|c|c|c|c|}
\hline \multirow[b]{2}{*}{$\begin{array}{l}\text { Model } \\
\text { parameter }^{2}\end{array}$} & \multirow[b]{2}{*}{ Model $\mathrm{R}^{2}$} & \multirow[b]{2}{*}{ Model F } & \multicolumn{9}{|c|}{ Variation source $(\mathrm{F})$} \\
\hline & & & $\begin{array}{c}T \\
(\mathrm{df}=2)\end{array}$ & $\begin{array}{c}I \\
(\mathrm{df}=2)\end{array}$ & $\begin{array}{c}F \\
(\mathrm{df}=1)\end{array}$ & $\begin{array}{c}T \times I \\
(\mathrm{df}=4)\end{array}$ & $\begin{array}{c}T \times F \\
(\mathrm{df}=2)\end{array}$ & $\begin{array}{c}I \times F \\
(\mathrm{df}=2)\end{array}$ & $\begin{array}{c}\mathrm{pH} \\
(\mathrm{df}=1)\end{array}$ & $\begin{array}{c}R P F \\
(\mathrm{df}=1)\end{array}$ & $\begin{array}{c}R e p \\
(\mathrm{df}=2)\end{array}$ \\
\hline$k$ & 0.91 & $20.8^{* * *}$ & $119^{* * *}$ & $47.4^{* * *}$ & $0.00^{\mathrm{NS}}$ & $0.55^{\mathrm{NS}}$ & $0.37^{\mathrm{NS}}$ & $0.23^{\mathrm{NS}}$ & $4.30^{*}$ & $0.01^{\mathrm{NS}}$ & $6.94^{* *}$ \\
\hline$C Y$ & 0.75 & $6.57^{* * *}$ & $39.8^{* * *}$ & $11.7^{* * *}$ & $0.29^{\mathrm{NS}}$ & $0.14^{\mathrm{NS}}$ & $0.36^{\mathrm{NS}}$ & $0.69^{\mathrm{NS}}$ & $0.07^{\mathrm{NS}}$ & $0.26^{\mathrm{NS}}$ & $1.99^{\mathrm{NS}}$ \\
\hline$W_{\infty}$ & 0.28 & $0.84^{\mathrm{NS}}$ & $0.98^{\mathrm{NS}}$ & $0.90^{\mathrm{NS}}$ & $0.97^{\mathrm{NS}}$ & $1.11^{\mathrm{NS}}$ & $2.23^{\mathrm{NS}}$ & $0.38^{\mathrm{NS}}$ & $0.50^{\mathrm{NS}}$ & $0.00^{\mathrm{NS}}$ & $0.76^{\mathrm{NS}}$ \\
\hline$W_{A}^{\infty}$ & 0.56 & $2.66^{*}$ & $15.2^{* * *}$ & $2.97^{\mathrm{NS}}$ & $0.07^{\mathrm{NS}}$ & $0.51^{\mathrm{NS}}$ & $2.56^{\mathrm{NS}}$ & $0.17^{\mathrm{NS}}$ & $0.12^{\mathrm{NS}}$ & $0.07^{\mathrm{NS}}$ & $0.12^{\mathrm{NS}}$ \\
\hline$t_{\text {clot }}$ & 0.98 & $88.0^{* * *}$ & $580^{* * *}$ & $126^{* * *}$ & $0.43^{\mathrm{NS}}$ & $14.9^{* * *}$ & $0.21^{\mathrm{NS}}$ & $0.40^{\mathrm{NS}}$ & $1.19^{\mathrm{NS}}$ & $0.13^{\mathrm{NS}}$ & $3.05^{\mathrm{NS}}$ \\
\hline$t_{\text {cut }}$ & 0.97 & $81.1^{* * *}$ & $541^{* * *}$ & $75.8^{* * *}$ & $0.11^{\mathrm{NS}}$ & $26.2^{\text {*** }}$ & $1.79^{\mathrm{NS}}$ & $0.75^{\mathrm{NS}}$ & $3.88^{\mathrm{NS}}$ & $0.01^{\mathrm{NS}}$ & $5.14^{*}$ \\
\hline$t_{\max }$ & 0.95 & $40.6^{* * *}$ & $269^{* * *}$ & $62.2^{* * *}$ & $0.00^{\mathrm{NS}}$ & $3.35^{*}$ & $0.20^{\mathrm{NS}}$ & $0.08^{\mathrm{NS}}$ & $0.55^{\mathrm{NS}}$ & $0.03^{\mathrm{NS}}$ & $2.56^{\mathrm{NS}}$ \\
\hline$t_{\max 2}$ & 0.91 & $15.8^{* * *}$ & $75.1^{* * *}$ & $10.1^{* *}$ & $2.41^{\mathrm{NS}}$ & $2.84^{*}$ & $2.09^{\mathrm{NS}}$ & $0.42^{\mathrm{NS}}$ & $3.64^{\mathrm{NS}}$ & $1.47^{\mathrm{NS}}$ & $0.93^{\mathrm{NS}}$ \\
\hline$t_{2 \max }$ & 0.89 & $17.7^{* * *}$ & $129^{* * *}$ & $17.0^{* * *}$ & $0.06^{\mathrm{NS}}$ & $0.19^{\mathrm{NS}}$ & $0.13^{\mathrm{NS}}$ & $0.45^{\mathrm{NS}}$ & $0.15^{\mathrm{NS}}$ & $0.08^{\mathrm{NS}}$ & $1.79^{\mathrm{NS}}$ \\
\hline$t_{2 \min }$ & 0.95 & $41.7^{* * *}$ & $274^{* * *}$ & $66.3^{* * *}$ & $0.18^{\mathrm{NS}}$ & $2.30^{\mathrm{NS}}$ & $0.09^{\mathrm{NS}}$ & $0.23^{\mathrm{NS}}$ & $1.33^{\mathrm{NS}}$ & $0.17^{\mathrm{NS}}$ & $4.14^{*}$ \\
\hline$t_{2 \max 2}$ & 0.65 & $2.22 *$ & $4.53^{*}$ & $1.48^{\mathrm{NS}}$ & $6.28^{*}$ & $0.20^{\mathrm{NS}}$ & $0.20^{\mathrm{NS}}$ & $1.66^{\mathrm{NS}}$ & $0.00^{\mathrm{NS}}$ & $4.11^{\mathrm{NS}}$ & $0.45^{\mathrm{NS}}$ \\
\hline$t_{2 \min 2}$ & 0.59 & $2.20^{*}$ & $8.61^{*}$ & $0.28^{\mathrm{NS}}$ & $0.79^{\mathrm{NS}}$ & $0.21^{\mathrm{NS}}$ & $0.05^{\mathrm{NS}}$ & $0.45^{\mathrm{NS}}$ & $3.28^{\mathrm{NS}}$ & $0.27^{\mathrm{NS}}$ & $0.78^{\mathrm{NS}}$ \\
\hline$t_{G^{\prime} 1}$ & 0.97 & $79.8^{* * *}$ & $474^{* * *}$ & $139^{* * *}$ & $0.09^{\mathrm{NS}}$ & $21.7^{* * *}$ & $0.91^{\mathrm{NS}}$ & $0.81^{\mathrm{NS}}$ & $4.35^{*}$ & $0.04^{\mathrm{NS}}$ & $3.64^{*}$ \\
\hline$t_{G^{\prime} 30}$ & 0.97 & $72.0^{* * *}$ & $476^{* * *}$ & $68.7^{* * *}$ & $0.02^{\mathrm{NS}}$ & $24.2^{* * *}$ & $1.33^{\mathrm{NS}}$ & $1.13^{\mathrm{NS}}$ & $5.26^{*}$ & $0.03^{\mathrm{NS}}$ & $3.86^{*}$ \\
\hline$t_{G^{\prime} 60}$ & 0.78 & $7.54^{* * *}$ & $51.4^{* * *}$ & $4.49^{*}$ & $1.21^{\mathrm{NS}}$ & $0.83^{\mathrm{NS}}$ & $0.36^{\mathrm{NS}}$ & $0.48^{\mathrm{NS}}$ & $0.30^{\mathrm{NS}}$ & $0.88^{\mathrm{NS}}$ & $2.76^{\mathrm{NS}}$ \\
\hline$t_{F 30}$ & 0.96 & $58.3^{* * *}$ & $394^{* * *}$ & $45.2^{* * *}$ & $0.01^{\mathrm{NS}}$ & $21.7^{* * *}$ & $1.21^{\mathrm{NS}}$ & $1.43^{\mathrm{NS}}$ & $4.55^{*}$ & $0.02^{\mathrm{NS}}$ & $3.33^{*}$ \\
\hline$t_{F 60}$ & 0.73 & $5.85^{* * *}$ & $39.8^{* * *}$ & $2.69^{\mathrm{NS}}$ & $1.26^{\mathrm{NS}}$ & $0.52^{\mathrm{NS}}$ & $0.41^{\mathrm{NS}}$ & $0.53^{\mathrm{NS}}$ & $0.22^{\mathrm{NS}}$ & $0.88^{\mathrm{NS}}$ & $2.62^{\mathrm{NS}}$ \\
\hline $\tan \delta_{30}$ & 0.997 & $795^{* * *}$ & $6,647^{* * *}$ & $1.17^{\mathrm{NS}}$ & $2.39^{\mathrm{NS}}$ & $39.8^{* * *}$ & $4.33^{*}$ & $1.68^{\mathrm{NS}}$ & $0.60^{\mathrm{NS}}$ & $0.49^{\mathrm{NS}}$ & $1.45^{\mathrm{NS}}$ \\
\hline $\tan \delta_{60}$ & 0.96 & $44.7 * * *$ & $361^{* * *}$ & $2.09^{\mathrm{NS}}$ & $0.12^{\mathrm{NS}}$ & $2.96^{*}$ & $2.48^{\mathrm{NS}}$ & $1.89^{\mathrm{NS}}$ & $2.38^{\mathrm{NS}}$ & $0.01^{\mathrm{NS}}$ & $0.79^{\mathrm{NS}}$ \\
\hline
\end{tabular}

${ }^{1}$ Number of observations $=54 ; T=$ temperature; $I=$ percentage of inulin; $F=$ percentage of fat; $T \times I=$ temperature $\times$ inulin interaction; $T \times F$, temperature $\times$ fat interaction; $I \times F$, inulin $\times$ fat interaction; $R P F=$ protein:fat ratio; $R e p=$ replication; $\mathrm{F}=$ ANOVA $F$-statistic

${ }^{2} k=$ kinetic rate constant $\left(\min ^{-1}\right)$ for the syneresis process; $C Y=\operatorname{curd}$ yield $; W_{\infty}=$ mass of whey drained $(\mathrm{g})$ at infinite time; $W_{A}=$ total accumulated whey mass $(\mathrm{g}) ; t_{\text {clot }}=$ clotting time; $t_{\text {cut }}=$ cutting time; $t_{\max }=$ elapsed time since enzyme addition to the first maximum of the first derivative; $t_{\max 2}=$ time to the second maximum of the first derivative; $t_{2 \max }=$ elapsed time since enzyme addition to the first maximum of the second derivative; $t_{2 \min }=$ time to the first minimum of the second derivative; $t_{2 \max 2}=$ time to the second maximum of the second derivative; $t_{2 \min 2}=$ times to the second minimum of the second derivative; $t_{G^{\prime \prime}}=$ gelation time; $t_{G^{\prime} 30}=$ time when $G^{\prime}$ reached a value of $30 \mathrm{~Pa} ; t_{G^{\prime \prime} 60}=$ time when $G^{\prime}$ reached a value of $60 \mathrm{~Pa} ; t_{F 30}=$ elapsed time between $G^{\prime}=1 \mathrm{~Pa}$ and $G^{\prime}=30 \mathrm{~Pa}$; $t_{F 60}=$ elapsed time between $G^{\prime}=1 \mathrm{~Pa}$ and $G^{\prime}=60 \mathrm{~Pa}$; $\tan \delta_{30}=\operatorname{the}$ value of $\tan \delta(\tan \delta$ $=G^{\prime \prime} / G^{\prime}$, where $G^{\prime}=$ storage modulus and $G^{\prime \prime}=$ loss modulus) when $G^{\prime \prime}=30 \mathrm{~Pa}$; $\tan \delta_{60}=$ the value of $\tan \delta$ when $G^{\prime \prime}=60 \mathrm{~Pa}$.

$* P<0.05 ; * * P<0.001 ; * * * P<0.0001$ 
inulin concentration and its structure (amorphous or crystalline), the temperature of preparation, and the presence of small crystals capable of inducing the crystallization. Kim et al. (2001) formed gels with a minimum concentration of $10 \%$ inulin, after heating the solution at $70^{\circ} \mathrm{C}$ and subsequent cooling at $25^{\circ} \mathrm{C}$ for $24 \mathrm{~h}$. They found that by increasing the concentration of inulin, gels could be formed at lower temperatures. They also obtained gels through shearing of the solution at $25^{\circ} \mathrm{C}$, noting that the gelation capacity increases with the speed of shearing.

Inulin gels are formed by a network of small crystals that retain water inside them and the gelation mechanism is induced by the presence of seed crystals (Kim et al., 2001; Glibowski and Pikus, 2011). The crystallization rate is reduced with the increase in preparation temperature due to the increase in solubility and in the fusion of crystals. As a result, the number of small crystals capable of inducing the remaining crystallization is lower, and fewer crystals cause formation of a gel with a weaker structure (Bot et al. 2004; Glibowski and Pikus, 2011). Guggisberg et al. (2009) found that the inulin addition did not affect the casein network in low-fat yogurt. They concluded that the inulin supports the structure by building up of a second network, not visible by confocal laser scanning microscopy.

As shown in Table 3, the addition of inulin to reconstituted milk at levels from 3 to $6 \%$ produced a significant decrease in visual parameters, $t_{\text {clot }}$ and $t_{\text {cut }}$, as well as in the NIR backscatter parameters $t_{\max }, t_{\max 2}, t_{2 \max }$, and $t_{2 \min }$. Regarding rheological parameters, significant decreases in $t_{G^{\prime} 1}$ and $t_{G^{\prime} 30}$ were observed with the increase in the concentration of inulin, whereas, in the case of $t_{G^{\prime} 60}$ and $t_{F 30}$, the decline in these parameters produced by the increase in inulin concentration from 3 to $6 \%$ was not significant. Castillo et al. (2003b) claimed that the first maximum of the first NIR light backscatter profile derivative as a function of time is correlated with the kinetics of casein micelle aggregation, whereas the second maximum of the first derivative contains information about gel firming.

Figure 4 clearly showed that the addition of inulin induced the split of the light backscatter profiles with the appearance of a shoulder (Figure 4a) shortly after

Table 3. Influence of main effects (temperature and inulin concentration) on optical, rheological and syneresis parameters $^{1}$

\begin{tabular}{|c|c|c|c|c|c|c|}
\hline \multirow[b]{3}{*}{ Item $^{2}$} & \multicolumn{6}{|c|}{ Main effect } \\
\hline & \multicolumn{3}{|c|}{ Temperature $\left({ }^{\circ} \mathrm{C}\right)$} & \multicolumn{3}{|c|}{ Inulin concentration (\%) } \\
\hline & 27 & 32 & 37 & 0 & 3 & 6 \\
\hline$k\left(\min ^{-1}\right)$ & $0.024^{\mathrm{a}}$ & $0.029^{\mathrm{b}}$ & $0.035^{\mathrm{c}}$ & $0.033^{\mathrm{a}}$ & $0.029^{\mathrm{b}}$ & $0.025^{c}$ \\
\hline$C Y(\%)$ & $31.5^{\mathrm{a}}$ & $29.1^{\mathrm{b}}$ & $25.8^{\mathrm{c}}$ & $27.3^{\mathrm{a}}$ & $28.7^{\mathrm{b}}$ & $30.4^{\mathrm{c}}$ \\
\hline$W_{\infty}(\mathrm{g})$ & $50.3^{\mathrm{a}}$ & $49.6^{\mathrm{a}}$ & $50.3^{\mathrm{a}}$ & $50.0^{\mathrm{a}}$ & $50.0^{\mathrm{a}}$ & $50.2^{\mathrm{a}}$ \\
\hline$W_{A}(\mathrm{~g})$ & $47.4^{\mathrm{a}}$ & $48.2^{\mathrm{a}}$ & $49.9^{\mathrm{b}}$ & $49.1^{\mathrm{a}}$ & $48.5^{\mathrm{ab}}$ & $47.9^{\mathrm{b}}$ \\
\hline$t_{\mathrm{clot}}(\mathrm{min})$ & $17.2^{\mathrm{a}}$ & $11.6^{\mathrm{b}}$ & $9.36^{\mathrm{c}}$ & $14.8^{\mathrm{a}}$ & $12.4^{\mathrm{b}}$ & $11.0^{\mathrm{c}}$ \\
\hline$t_{\text {cut }}(\min )$ & $65.9^{\mathrm{a}}$ & $30.0^{\mathrm{b}}$ & $20.7^{\mathrm{c}}$ & $49.0^{\mathrm{a}}$ & $35.7^{\mathrm{b}}$ & $31.9^{\mathrm{c}}$ \\
\hline$t_{\max }(\min )$ & $12.3^{\mathrm{a}}$ & $9.12^{\mathrm{b}}$ & $7.77^{\mathrm{c}}$ & $10.9^{\mathrm{a}}$ & $9.55^{\mathrm{b}}$ & $8.70^{\mathrm{c}}$ \\
\hline$t_{\max 2}(\min )$ & $20.6^{\mathrm{a}}$ & $13.4^{\mathrm{b}}$ & $7.94^{\mathrm{c}}$ & $15.8^{\mathrm{a}}$ & $13.4^{\mathrm{b}}$ & $12.8 b^{c}$ \\
\hline$t_{2 \max }(\min )$ & $9.78^{\mathrm{a}}$ & $7.55^{\mathrm{b}}$ & $6.43^{\mathrm{c}}$ & $8.59^{\mathrm{a}}$ & $7.8^{\mathrm{b}}$ & $7.35^{\mathrm{c}}$ \\
\hline$t_{2 \min }(\min )$ & $14.0^{\mathrm{a}}$ & $10.6^{\mathrm{b}}$ & $8.91^{\mathrm{c}}$ & $12.6^{\mathrm{a}}$ & $11.0^{\mathrm{b}}$ & $9.98^{\mathrm{c}}$ \\
\hline$t_{2 \max 2}(\min )$ & - & $11.5^{\mathrm{a}}$ & $6.51^{\mathrm{b}}$ & - & $10.9^{\mathrm{a}}$ & $10.4^{\mathrm{a}}$ \\
\hline$t_{2 \min 2}(\min )^{\prime}$ & $19.8^{\mathrm{a}}$ & $14.3^{\mathrm{b}}$ & $8.75^{\mathrm{bc}}$ & $14.6^{\mathrm{a}}$ & $14.2^{\mathrm{a}}$ & $14.0^{\mathrm{a}}$ \\
\hline$t_{G^{\prime \prime} 1}(\min )$ & $21.9^{\mathrm{a}}$ & $14.1^{\mathrm{b}}$ & $11.6^{\mathrm{c}}$ & $19.0^{\mathrm{a}}$ & $15.3^{\mathrm{b}}$ & $13.3^{\mathrm{c}}$ \\
\hline$t_{G^{\prime 30}}(\min )$ & $70.4^{\mathrm{a}}$ & $31.5^{\mathrm{b}}$ & $22.1^{\mathrm{c}}$ & $52.3^{\mathrm{a}}$ & $37.9^{\mathrm{b}}$ & $33.7^{\mathrm{c}}$ \\
\hline$t_{G^{\prime} 60}(\min )$ & $112^{\mathrm{a}}$ & $48.6^{\mathrm{b}}$ & $33.0^{\mathrm{b}}$ & $78.8^{\mathrm{a}}$ & $61.1^{\mathrm{b}}$ & $54.4^{\mathrm{b}}$ \\
\hline$t_{F 30}(\mathrm{~min})$ & $48.5^{\mathrm{a}}$ & $17.4^{\mathrm{b}}$ & $10.5^{\mathrm{c}}$ & $33.3^{\mathrm{a}}$ & $22.4^{\mathrm{b}}$ & $20.5^{\mathrm{b}}$ \\
\hline$t_{F 60}(\min )$ & $90.9^{\mathrm{a}}$ & $34.5^{\mathrm{b}}$ & $21.4^{\mathrm{b}}$ & $59.6^{\mathrm{a}}$ & $45.5^{\mathrm{ab}}$ & $40.8^{\mathrm{b}}$ \\
\hline $\tan \delta_{30}($ dimensionless $)$ & $14.0^{\mathrm{a}}$ & $15.0^{\mathrm{b}}$ & $16.7^{\mathrm{c}}$ & $15.2^{\mathrm{a}}$ & $15.2^{\mathrm{a}}$ & $15.2^{\mathrm{a}}$ \\
\hline $\tan \delta_{60}$ (dimensionless) & $13.8^{\mathrm{a}}$ & $14.6^{\mathrm{b}}$ & $16.2^{\mathrm{c}}$ & $15.0^{\mathrm{a}}$ & $14.8^{\mathrm{a}}$ & $14.9^{\mathrm{a}}$ \\
\hline
\end{tabular}

${ }^{\mathrm{a}-\mathrm{c}}$ Least squares means with same letters are not significantly different $(P<0.05)$.

${ }^{1}$ Number of replications $=3$; number of observations $=27$.

${ }^{2} k=$ kinetic rate constant $\left(\min ^{-1}\right)$ for the syneresis process; $C Y=$ curd yield; $W_{\infty}=$ mass of whey drained $(\mathrm{g})$ at infinite time; $W_{A}=$ total accumulated whey mass $(\mathrm{g}) ; t_{\text {clot }}=$ clotting time; $t_{\text {cut }}=$ cutting time; $t_{\max }=$ elapsed time since enzyme addition to the first maximum of the first derivative; $t_{\max 2}=$ time to the second maximum of the first derivative; $t_{2 \max }=$ elapsed time since enzyme addition to the first maximum of the second derivative; $t_{2 \min }=$ time to the first minimum of the second derivative; $t_{2 \max 2}=$ time to the second maximum of the second derivative; $t_{2 \min 2}=$ times to the second minimum of the second derivative; $t_{G^{\prime \prime} 1}=$ gelation time; $t_{G^{\prime \prime} 30}=$ time when $G^{\prime}$ reached a value of $30 \mathrm{~Pa} ; t_{G^{\prime} 60}=$ time when $G^{\prime}$ reached a value of $60 \mathrm{~Pa}$; $t_{F 30}=$ elapsed time between $G^{\prime}=1 \mathrm{~Pa}$ and $G^{\prime}=30 \mathrm{~Pa} ; t_{F 60}=$ elapsed time between $G^{\prime}=1 \mathrm{~Pa}$ and $G^{\prime}=60 \mathrm{~Pa}$; tan $\delta_{30}=$ the value of $\tan \delta$ $\left(\tan \delta=G^{\prime \prime} / G^{\prime}\right.$, where $G^{\prime}=$ storage modulus and $G^{\prime \prime}=$ loss modulus) when $G^{\prime}=30 \mathrm{~Pa}$; $\tan \delta_{60}=$ the value of $\tan \delta$ when $G^{\prime}=60 \mathrm{~Pa}$. 
$t_{\max }$. This phenomenon was accentuated with increasing inulin concentration, inducing the appearance of a $t_{\max 2}$ (Figure $4 \mathrm{~b}$ ). The appearance of this second maximum induced the corresponding changes in the second derivative (Figure 4c). The inulin effect is especially evident in the first part of the profile where increasing the inulin concentration increased the slope, generating a clear separation of the curves in the corresponding derivatives.

The observed phenomenon was attributed to the differential effect of the addition of inulin on the 2 reactions involved in curd assembly (i.e., para- $\kappa-\mathrm{CN}$ micelle aggregation and curd firming). In other words, the addition of inulin seems to promote more intensively
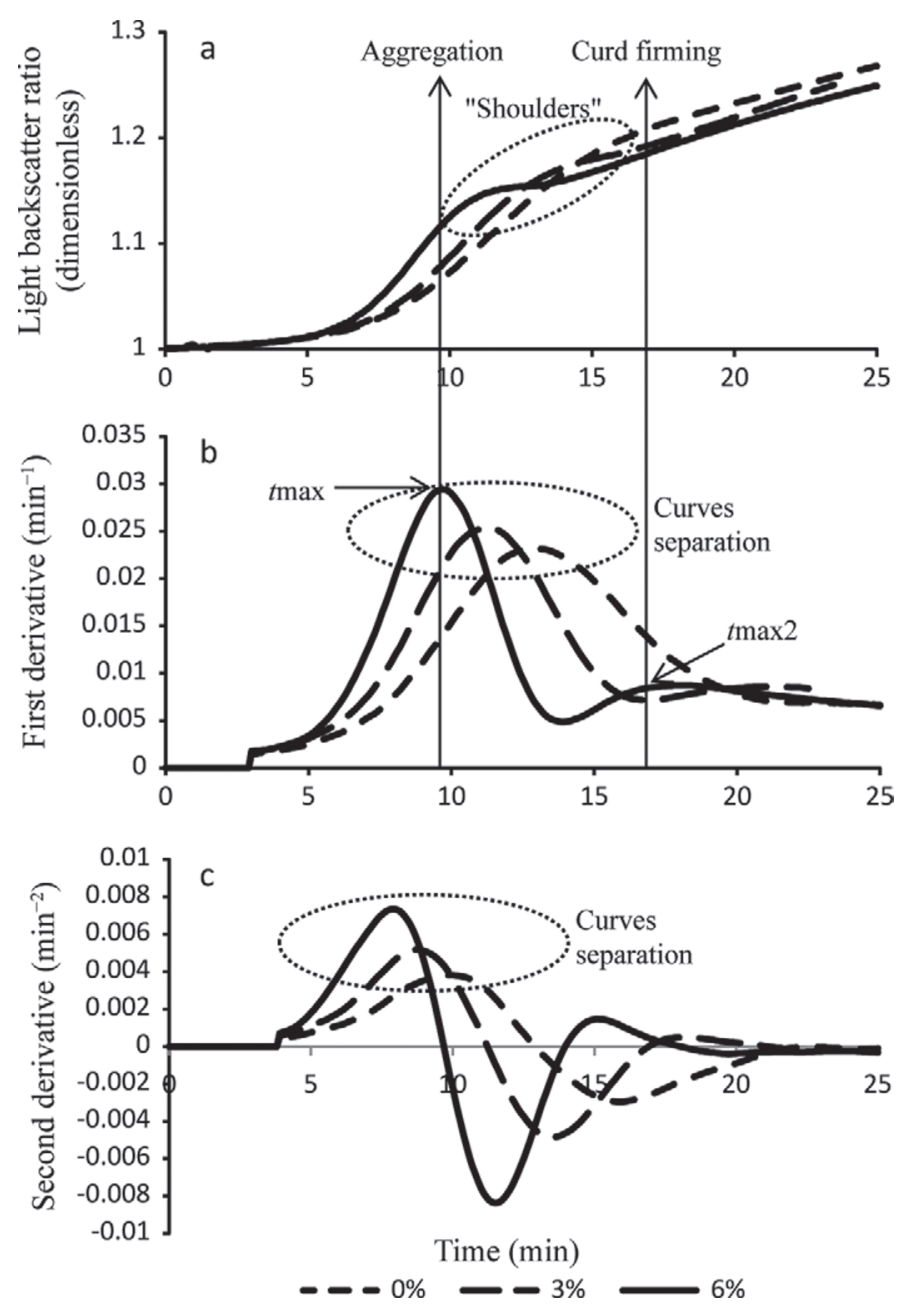

Figure 4. Effect of inulin concentration on apparition of a shoulder in the light backscatter ratio profile versus time (a) and in the separation of its first derivative (b) and second derivative (c). Data were obtained by averaging the measurements for 3 replications at $27^{\circ} \mathrm{C}, 0.2 \%$ fat, and different levels of inulin. $t_{\max }=$ elapsed time since enzyme addition to the first maximum of the first derivative; $t_{\max 2}=$ time to the second maximum of the first derivative. the micellar aggregation processes (i.e., clear increase of the magnitude of $R_{\max }$ when increasing the inulin concentration) while having a less marked influence on the gel firming reaction (i.e., more similar values of $R_{\max 2}$ regardless of the inulin concentration). The described phenomenon seems logical, given the inulin capacity to form a network of small microcrystals that retain water inside them. This suggests the hypothesis that the inulin accelerates the reaction of aggregation by a combined effect of relative concentration of solutes in the matrix and an increase in the enzyme concentration; that is to say, the inulin retains part of the water and the increase in the concentration of enzyme and casein facilitates both the hydrolysis of $\kappa-\mathrm{CN}$ and the aggregation reaction.

Figure 5 shows the evolution of $G^{\prime}$ and $\tan \delta$ during skim milk coagulation $(0.2 \%$ fat $)$ at $32^{\circ} \mathrm{C}$ in the presence of different concentrations of inulin. It was observed that when the addition of inulin increases, the firming rate also increased. This resulted in a shorter base line and a higher value of $G^{\prime}$. That is to say, at the same coagulation time, gels with the larger inulin concentration were firmer; in other words, a certain level of firmness, for example $G^{\prime}=30 \mathrm{~Pa}$, was reached in less time in the presence of inulin.

The time required for the firmness of the gel to increase from 1 to $30 \mathrm{~Pa}$ (represented by the parameter $\left.t_{F 30}\right)$ only showed a significant decrease $(P<0.05)$ when adding $6 \%$ inulin and no effect of this factor was observed on the parameters $\tan \delta_{30}$ and $\tan \delta_{60}$.

Fagan et al. (2006) found a significant decrease in the $t_{G^{\prime} 1}$ when adding inulin concentrations of 2 to $3 \%$ to pasteurized skim milk and a limited effect on the coagulum firming rate, which was attributed to the inability of inulin to form complex gel structures. Micrographs made through confocal laser scanning microscopy to yogurt with 3.5 and $0.2 \%$ fat and various levels of inulin showed no significant differences between the microstructures of gels with inulin addition, except for a slight decrease in the cohesiveness of the protein structure and larger pores (Guggisberg et al., 2009). Fagan et al. (2006) did not note significant differences in the microstructure of milk gels with and without inulin. As an increase in $\tan \delta$ corresponds with larger pores, more permeability, and greater ability to changes in the type or number of links of the gel network (van Vliet et al., 1991; Castillo et al., 2006b), the lack of effect of the inulin addition on $\tan \delta$ in our study suggests that, indeed, inulin does not significantly affect the gel microstructure.

Temperature Effect. Table 3 shows that the increase in the temperature produced a significant decrease $(P<0.05)$ in all light backscatter parameters $\left(t_{\max }, t_{\max 2}, t_{2 \max }, t_{2 \min }, t_{2 \max 2}\right.$, and $\left.t_{2 \min 2}\right)$ that were gener- 


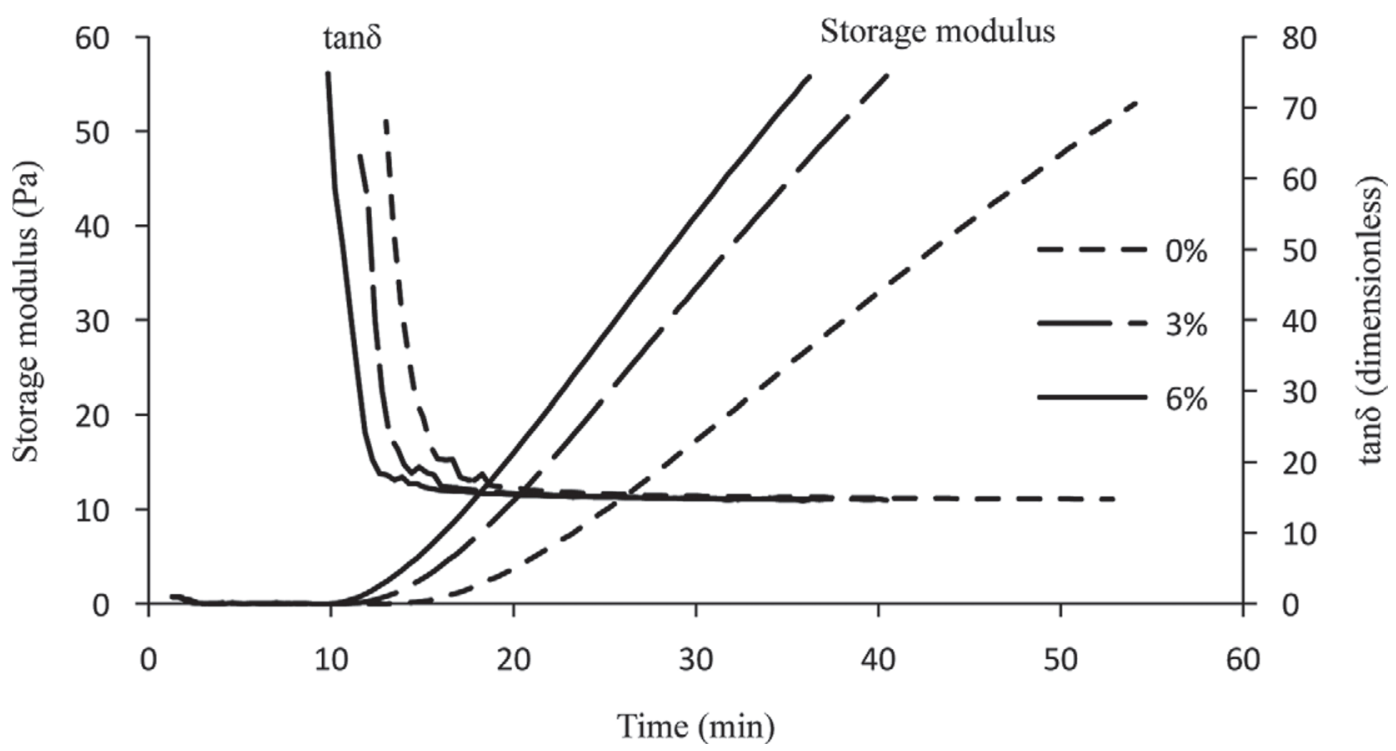

Figure 5. Effect of inulin concentration on the storage modulus $\left(G^{\prime}\right)$ and $\tan \delta\left(\tan \delta=G^{\prime \prime} / G^{\prime \prime}\right.$, where $G^{\prime \prime}=$ loss modulus). Tests were made per triplicate at $32^{\circ} \mathrm{C}$ with $0.2 \%$ fat and different concentrations of inulin.

ated during the reconstituted milk-coagulation process. The same significant effect was observed on the visual parameters $t_{\text {clot }}$ and $t_{\text {cut }}$, and on the rheological parameters $t_{G^{\prime}} 1, t_{G^{\prime} 30}, t_{F 30}, t_{G^{\prime \prime} 60}$, and $t_{F 60}$, but in the last 2 the differences were significant only from 27 to $37^{\circ} \mathrm{C}$. When increasing coagulation temperature from 27 to $37^{\circ} \mathrm{C}$, we could observe a reduction of $69 \%$ for the parameter $t_{\text {cut }}$ and $37 \%$ for the parameter $t_{\max }$.

The optical parameter $R_{\max }^{\prime}$, defined as the maximum value of change in light backscatter profile/change in time (where $R^{\prime}=\mathrm{d} R / \mathrm{d} t$ ), was used to calculate an approximation of the temperature coefficients $\left(Q_{10}\right)$ under the condition of this study $\left(27-37^{\circ} \mathrm{C}\right)$. The apparent values of $Q_{10}$ obtained for $0.2 \%$ milk fat were $3.1,2.8$, and 2.4 for samples with 0,3 , and $6 \%$ inulin, respectively. It allowed noting that the inulin addition attenuates the effect of the temperature on the coagulation rate. Castillo et al. (2003a) calculated the value of $Q_{10}$ in the temperature interval of 25 to $35^{\circ} \mathrm{C}$, using the same optical parameter. They obtained a value of 2.2 , which is very close to the values found in the current study. The difference can be attributed to the temperature interval evaluated in the study of Castillo et al. (2003a), which was lower. It is also necessary to specify that the values of $Q_{10}$, which were calculated from the optical parameter $R_{\text {max }}^{\prime}$, reflect the combined effect of the hydrolysis phase of the $\kappa-\mathrm{CN}$ and the beginning of the aggregation phase.

The rheological coagulation parameters showed a significant reduction with the temperature increase. When the temperature increased from 27 to $37^{\circ} \mathrm{C}$, the $t_{G^{\prime \prime}}$ and the $t_{G^{\prime} 30}$ were reduced by 47 and $69 \%$, respectively, whereas $t_{\max }$ decreased by $37 \%$.

The interaction between the temperature and the inulin concentration had significant effects on several parameters related to the coagulation process, including $t_{\text {clot }}, t_{\text {cut }}$, and $t_{G^{\prime \prime} 1}$. Figure 6 shows the effect of the interaction $T \times I$ on $t_{G^{\prime \prime} 1}$. As the inulin concentration increased, $t_{G^{\prime \prime} 1}$ decreased, but the effect was more pronounced at lower temperatures. From Table 3 and Figure 6, it is clear that the rheological effect of temperature predominates over the inulin effect (compare the effect of inulin and temperature on least squares means values for $t_{G^{\prime \prime}}, t_{G^{\prime} 30}, t_{G^{\prime \prime} 60}, t_{F 30}$, and $\left.t_{F 60}\right)$. The inulin particles agglomerate, retaining water inside them and contributing to increasing the casein gel strength. The effect is more pronounced at $27^{\circ} \mathrm{C}$, probably as a result of the increased number of seed crystals with lower temperatures, which originates the formation of a gel with stronger structure (Bot et al., 2004; Glibowski and Pikus, 2011) that probably retains more water.

The interaction $T \times I$ on the variable $\tan \delta_{30}$ was also significant. The final value of $\tan \delta_{30}$ increased with temperature, but the inulin concentration appeared to widen or reduce this effect, depending on the temperature being considered. Figure 7 shows that at $27^{\circ} \mathrm{C}, \tan \delta_{30}$ increased with the increase of inulin concentration, but at $37^{\circ} \mathrm{C}$ the inulin effect was opposite; that is to say, $\tan \delta_{30}$ decreased when the inulin percentage increased. The effort required to deform a material is inversely proportional to the diameter of particles (Gerberich, 1997); therefore, in gels prepared at higher tempera- 


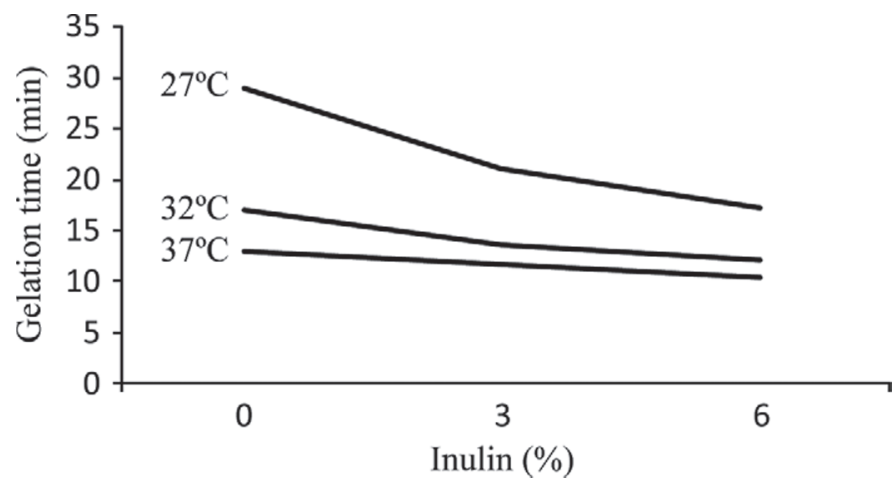

Figure 6. Effect of the interaction temperature $\times$ inulin on gelation time $\left[t_{G^{\prime}}\right.$, defined as the time when the gels had a storage modulus $\left.\left(G^{\prime}\right)=1\right]$. Tests were made per triplicate with $0.2 \%$ fat.

ture, the smaller size of the inulin particles could be the cause of the decline in $\tan \delta$. The particle sizes are larger at low temperature, which implies a minor effort of deformation and, therefore, an increase in $\tan \delta$.

Fat Concentration Effect. The 2 levels of fat concentration in reconstituted milk evaluated in this study $(0.2-1.5 \%)$ only had significant effect $(P<0.005)$ on the optical parameter $t_{2 \max 2}$, which increased with decreasing fat concentration. Although the differences were not significant for the rest of the time parameters evaluated, the observed trend was consistent with that for $t_{2 \max 2}$. Thus, by reducing the level of fat, there was a very consistent increase in the optical parameters $t_{2 \max }$, $t_{2 \min }, t_{\max 2}$, and $t_{2 \min 2}$; in the rheological parameters $t_{G^{\prime 1}}$ and $t_{G^{\prime} 30}$; and in the visual parameters $t_{\text {clot }}$ and $t_{\text {cut }}$. This observed trend might indicate that the gels coagulated slightly more slowly when having less fat. Fat removal was associated with a higher protein:fat ratio and higher water content in the experimental conditions of

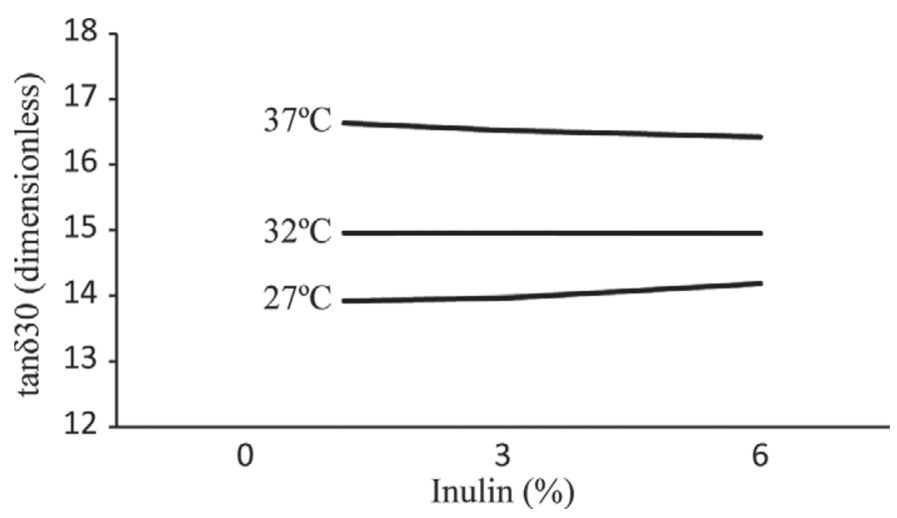

Figure 7. Effect of the interaction temperature $\times$ inulin on $\tan \delta_{30}$ [the value of $\tan \delta\left(\tan \delta=G^{\prime \prime} / G^{\prime}\right.$, where $G^{\prime}=$ storage modulus and $G^{\prime \prime}=$ loss modulus) when $\left.G^{\prime}=30 \mathrm{~Pa}\right]$. Tests were made per triplicate with $0.2 \%$ fat. this study (constant level of protein). The latest fact probably caused a small phenomenon of micellar dilution that might have slightly reduced the aggregation and firming rates.

These results are consistent with those observed by Fenelon and Guinee (1999), who observed a reduction in the gelation time and an increase in the strength of the curd (i.e., $\mathrm{G}^{\prime}$ ) when increasing the fat content in the milk. Agreeing with our results, Calvo (2002) observed that the clotting time was significantly larger in skimmed cow milk than in whole milk, whereas Lucey et al. (1998) did not obtain significant differences in the gelation time of acid gels with levels of $0,1.5$, and $3.5 \%$ fat. When the membrane of the native fat globules of milk is intact, they do not participate in the formation of the gel network, as they do not interact with the casein particles. Therefore, the fat globules only take part as an inert filler (structure breaker), filling the empty spaces within the matrix of casein (van Vliet, 1988). This justifies the small magnitude of the observed nonsignificant trends.

\section{Experimental Factors Effect on the Syneresis and the Curd Yield}

The Kinetics of Syneresis. The expulsion of whey of the milk enzymatic gels followed first-order kinetics that was properly estimated using Equation 1. The values of the coefficient of determination and the standard error of prediction for the regression between the observed and estimated data were $0.980 \pm 0.002$ and $2.75 \pm 0.18 \mathrm{~g}$, respectively, with $48.50 \pm 1.76 \mathrm{~g}$ being the average of the total amount of whey expelled by the samples.

Figure 8 shows the syneresis (accumulated whey mass) according to the elapsed time since the cutting of the curd. In this figure, the fitting was conducted applying Equation 1 to the experimental data of samples at $32^{\circ} \mathrm{C}$ with $1.5 \%$ fat, without inulin addition. Each point in the graph represents the average of 3 trials (i.e., 3 independent replicates). In addition, each one of these 3 independent replicates was also calculated from the average of 3 syneresis measurement (see Experimental Design section).

In all treatments, as can be seen in Figure 8, the accumulated whey mass increased rapidly during the first 60 min after cutting, reaching values between 75 and $90 \%$ of the total mass of drained whey during the 150 min of each test. The kinetic rate constants for whey drainage $(k)$ for the 54 trials were in the range $2.91 \cdot 10^{-2}$ $\pm 6.07 \cdot 10^{-3} \mathrm{~min}^{-1}$. These values were on the same order of magnitude as the values reported by Calvo and Balcones (2000) and by Kaytanli et al. (1993) for gels obtained by enzymatic coagulation of skimmed cow milk. 


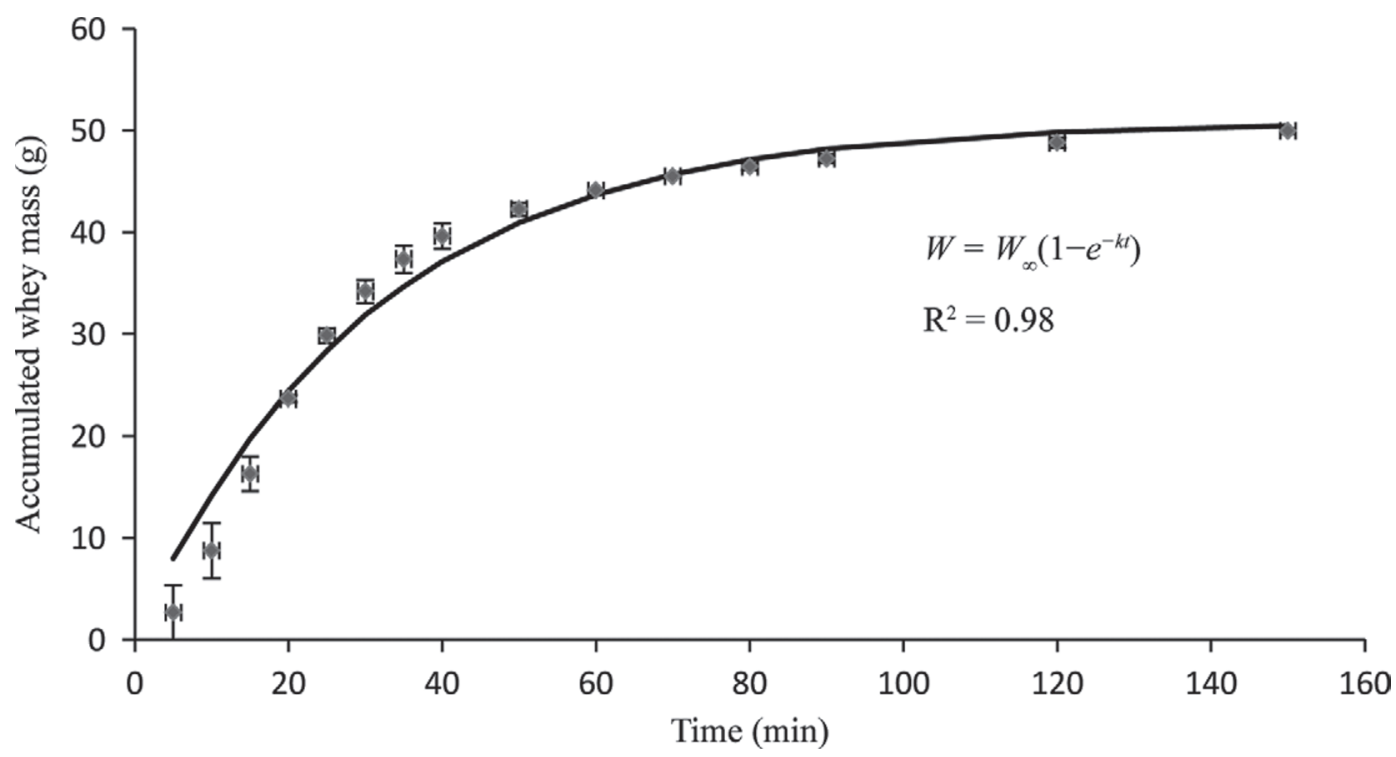

Figure 8. Kinetics of whey expulsion as a function of time. Time zero corresponds to the time at which the curd was cut [storage modulus $\left(G^{\prime}\right)=30 \mathrm{~Pa}$. The initial mass of milk was approximately $70 \mathrm{~g} . W=$ weight of the whey at time $t$; kinetic rate constant $(k)=0.033 \mathrm{~min}^{-1} ;$ mass $^{2}$ of whey drained at infinite time $\left(W_{\infty}\right)=50.8 \mathrm{~g}$. Error bars corresponded to the \pm 1 SD interval, with the average value being the middle point.

The global $Q_{10}$ for the drainage of whey process was calculated to be 1.46. Kaytanli et al. (1993) obtained a $Q_{10}$ value of 1.8 for the same type of gels.

Table 2 shows highly significant temperature effects on the $k$, the $\mathrm{CY}$, and the $W_{A}$. In addition, significant effects of the inulin concentration on $k$ and CY were observed. These effects will be discussed in detail below.

Inulin Concentration Effect. As shown in Table 3 , the increase in the inulin concentration within the concentration levels tested in this study produced a significant decrease $(P<0.05)$ in the $k$ and a significant increase $(P<0.05)$ in the CY. Inulin addition at a level of $6 \%$ produced a significant reduction in the $W_{A}$ but it had no effect on the $W_{\infty}$.

As is shown in Figure 5, the $\tan \delta$ value observed when the gels reached a hardness value $\geq 12$ to $15 \mathrm{~Pa}$ was approximately constant and independent of the inulin concentration. This indicates that its presence did not affect the gel ability for rearrangement and contraction. These data allow attributing the inulin inhibiting effect on syneresis to the inulin water-retention capacity. This increase in water retention is responsible for the observed increase in the CY.

Our results are consistent with those observed in yogurt by Guggisberg et al. (2009) and Brennan and Tudorica (2008). Those authors concluded that the addition of inulin at a concentration of $2 \%$ reduced the syneresis in low-fat yogurts at levels comparable with the control made with whole milk.

Temperature Effect. Table 3 shows the least squares means for the syneresis parameters $k, W_{\infty}$, and
$W_{A}$ and for the CY. The least squares means values for $k$ increased significantly $(P<0.05)$ when increasing the gelation temperature, whereas $\mathrm{CY}$ significantly decreased $(P<0.05)$. No significant temperature effect was observed on the $W_{\infty}$, whereas the parameter $W_{A}$ only showed significant differences between 27 and $37^{\circ} \mathrm{C}$. As expected, a larger $k$, which was associated with lower levels of inulin addition, was also related to increased drained whey mass and decreased CY. In addition, a high correlation was observed between the $k$ and the light backscatter parameters $R_{\max }$ and $R_{\max 2}$, which represent the rate of network formation (aggregation and gel firming). The Pearson correlation coefficients obtained between $k$ and those 2 light backscatter indices were 0.82 and $0.85(P<0.0001)$, respectively. These results confirm that faster coagulation reaction enhanced syneresis. Castillo et al. (2006b) observed the same phenomenon when studying the temperature effect on mixed gels (Cottage cheese).

Various studies have shown that both coagulation temperature and the temperature at which the syneresis reaction takes place exert an effect on the rate and degree of syneresis. Coagulation temperature affects the link-formation rate and the average lifespan of links, as well as the gel permeability, controlling its microstructure and rheological behavior (Lagoueyte et al., 1994; Lucey, 2002; Mishra et al., 2005), which exerts an indirect effect on subsequent curd draining after cutting. Temperatures also affected the CY, which increased when reducing the coagulation and syneresis temperatures. This is related to the reduction in the 
degree of syneresis, resulting in curds with higher moisture content.

Fat Concentration Effect. In spite of the nonstatistically significant effects, increasing fat concentration induced a slight decrease in the $k$ and an increase in CY. These results were not conclusive but concurred with previous studies, in which it was found that the volume of whey expelled was reduced by the increase in milk fat concentration (Marshall, 1982; Johnston and Murphy, 1984; Mateo et al., 2009). The fact that the differences observed in our study were not significant might be attributed to the little difference between the assessed levels of fat (0.2 and 1.5\%).

\section{CONCLUSIONS}

The inulin addition accelerated coagulation reactions and increased the milk gel strength without significantly affecting the ability of reorganization of its structure at the beginning of the whey release. The effect of inulin on coagulation reactions and gel firming was influenced not only by the concentration of inulin but also by the coagulation temperature, being greater at lower temperatures. The inulin concentration increase produced a significant decrease in the $k$ and the $W_{A}$ and, therefore, a significant increase in the $\mathrm{CY}$, as a result of the water-retention capability of inulin. Although the results of this study regarding fat concentration were not conclusive, they suggest that a reduction in the fat concentration might increase $t_{\text {clot }}$ and $t_{\text {cut }}$ and decreases the milk gel strength. These effects would be offset by inulin addition, as this produces contrary effects.

\section{ACKNOWLEDGMENTS}

During this research, O. Arango was supported by an Erasmus Mundus Project E2NHANCE grant and by Universidad de Nariño (Pasto, Colombia).

\section{REFERENCES}

AOAC International. 2000. Official Methods of Analysis. AOAC International, Washington, DC.

Bot, A., U. Erle, R. Vreeker, and W. G. M. Agterof. 2004. Influence of crystallisation conditions on the large deformation rheology of inulin gels. Food Hydrocoll. 18:547-556.

Brennan, C. S., and C. M. Tudorica. 2008. Carbohydrate-based fat replacers in the modification of the rheological, textural and sensory quality of yoghurt: Comparative study of the utilisation of barley beta-glucan, guar gum and inulin. Int. J. Food Sci. Technol. 43:824-833.

Calvo, M. M. 2002. Influence of fat, heat treatments and species on milk rennet clotting properties and glycomacropeptide formation. Eur. Food Res. Technol. 214:182-185.

Calvo, M. M., and E. Balcones. 2000. Some factors influencing the syneresis of bovine, ovine, and caprine milks. J. Dairy Sci. 83:17331739.
Castillo, M. 2001. Cutting time prediction in cheese making by backscatter of near infrared radiation. PhD Thesis. Department of Food Technology, University of Murcia, Spain.

Castillo, M., J. A. Lucey, and F. A. Payne. 2006a. The effect of temperature and inoculum concentration on rheological and light scatter properties of milk coagulated by a combination of bacterial fermentation and chymosin. Cottage cheese-type gels. Int. Dairy J. $16: 131-146$.

Castillo, M., J. A. Lucey, T. Wang, and F. A. Payne. 2006b. Effect of temperature and inoculum concentration on gel microstructure, permeability and syneresis kinetics. Cottage cheese type gels. Int. Dairy J. 16:153-163.

Castillo, M., F. A. Payne, C. L. Hicks, J. Laencina, and M.-B. López. 2003a. Effect of protein and temperature on cutting time prediction in goats' milk using an optical reflectance sensor. J. Dairy Res. 70:205-215.

Castillo, M., F. A. Payne, C. L. Hicks, and M. B. López. 2000. Predicting cutting and clotting time of coagulating goat's milk using diffuse reflectance: Effect of $\mathrm{pH}$, temperature and enzyme concentration. Int. Dairy J. 10:551-562.

Castillo, M. Z., F. A. Payne, C. L. Hicks, J. Laencina, and M.-B. M. López. 2003b. Modelling casein aggregation and curd firming in goats' milk from backscatter of infrared light. J. Dairy Res. 70:335-348.

European Parliament. 2006. Regulation (EC) No 1924/2006 of the European parliament and of the council of 20 December 2006 on nutrition and health claims made on foods. Off. J. Eur. Union 404:9-25.

Fagan, C. C., C. P. O'Donnell, P. J. Cullen, and C. S. Brennen. 2006. The effect of dietary fiber inclusion on milk coagulation kinetics. J. Food Eng. 77:261-268.

Fenelon, M. A., and T. P. Guinee. 1999. The effect of milk fat on Cheddar cheese yield and its prediction, using modifications of the Van Slyke cheese yield formula. J. Dairy Sci. 82:2287-2299.

Franck, A. 2002. Technological functionality of inulin and oligofructose. Br. J. Nutr. 87(Suppl. 2):S287-S291.

Gerberich, W. 1997. Grain boundary surfaces and interfaces in crystalline solids. Page 680 in Fundamentals of Interfacial Engineering. R. J. Stokes and D. F. Evans, ed. John Wiley \& Sons Inc., New York, NY.

Gijs, L., G. Piraprez, P. Perpète, S. Spinnler, and S. Collin. 2000. Retention of sulfur flavours by food matrix and determination of sensorial data independent of the medium composition. Food Chem. 69:319-330.

Glibowski, P., and S. Pikus. 2011. Amorphous and crystal inulin behavior in a water environment. Carbohydr. Polym. 83:635-639.

Guggisberg, D., J. Cuthbert-Steven, P. Piccinali, U. Bütikofer, and P. Eberhard. 2009. Rheological, microstructural and sensory characterization of low-fat and whole milk set yoghurt as influenced by inulin addition. Int. Dairy J. 19:107-115.

Hennelly, P. J., P. G. Dunne, M. O'Sullivan, and E. D. O'Riordan. 2006. Textural, rheological and microstructural properties of imitation cheese containing inulin. J. Food Eng. 75:388-395.

IDF (International Dairy Federation). 2002. Milk and milk productsDetermination of nitrogen content-Routine method using combustion according to the Dumas principle. IDF Standard 185. IDF, Brussels, Belgium.

IDF (International Dairy Federation). 2007. Milk-Determination of the total milk-clotting activity of bovine rennets. IDF Standard 157. IDF, Brussels, Belgium.

Johnston, D. E., and R. J. Murphy. 1984. Effects of fat content on properties of rennet-induced milk-gels. Milchwissenschaft 39:585587.

Kalyani Nair, K., S. Kharb, and D. K. Thompkinson. 2010. Inulin dietary fiber with functional and health attributes - A review. Food Rev. Int. 26:189-203.

Kaytanli, M., Y. K. Erdem, and I. M. Tamer. 1993. Factors affecting whey drainage rate of renneted skim milk gels: A kinetic approach. Egyptian J. Dairy Sci. 21:185-191.

Kim, Y., M. N. Faqih, and S. S. Wang. 2001. Factors affecting gel formation of inulin. Carbohydr. Polym. 46:135-145. 
Kip, P., D. Meyer, and R. H. Jellema. 2006. Inulins improve sensoric and textural properties of low-fat yoghurts. Int. Dairy J. 16:1098-1103.

Lagoueyte, N., J. Lablee, A. Lagaude, and B. Tarodo de la Fuente. 1994. Temperature affects microstructure of renneted milk gel. J. Food Sci. 59:956-959.

Lucey, J. A. 2002. Formation and physical properties of milk protein gels. J. Dairy Sci. 85:281-294.

Lucey, J. A., C. T. Teo, P. A. Munro, and H. Singh. 1998. Microstructure, permeability and appearance of acid gels made from heated skim milk. Food Hydrocoll. 12:159-165.

Marshall, R. J. 1982. An improved method for measurement of the syneresis of curd formed by rennet action on milk. J. Dairy Res. 49:329-336.

Mateo, M. J., C. D. Everard, C. C. Fagan, C. P. O'Donnell, M. Castillo, F. A. Payne, and D. J. O'Callaghan. 2009. Effect of milk fat concentration and gel firmness on syneresis during cheeses-making. Int. Dairy J. 19:264-268.

Mishra, R., S. Govindasamy-Lucey, and J. A. Lucey. 2005. Rheological properties of rennet-induced gels during the coagulation and cutting process: Impact of processing conditions. J. Texture Stud. $36: 190-212$.

Modzelewska-Kapituła, M., and L. Kłębukowska. 2009. Investigation of the potential for using inulin HPX as a fat replacer in yoghurt production. Int. J. Dairy Technol. 62:209-214.

Pagliarini, E., and N. Beatrice. 1994. Sensory and rheological properties of low-fat 'Pasta Filata' cheese. J. Dairy Res. 61:299-304.

Paseephol, T., D. M. Small, and F. Sherkat. 2008. Rheology and texture of set yogurt as affected by inulin addition. J. Texture Stud. 39:617-634.
Peri, C., M. Lucisano, and E. Donati. 1985. Studies on coagulation of milk ultrafiltration retentates. II. Kinetics of whey syneresis. Milchwissenschaft 40:650-652.

Roberfroid, M., and J. Slavin. 2000. Nondigestible oligosaccharides. Crit. Rev. Food Sci. Nutr. 40:461-480.

Roberfroid, M. B. 2007. Inulin-type fructans: Functional food ingredients. J. Nutr. 137(Suppl.):2493S-2502S.

Tabayehnejad, N., M. Castillo, and F. A. Payne. 2011. Comparison of total milk-clotting activity measurement precision using the Berridge clotting time method and a proposed optical method. J. Food Eng. 108:549-556.

Tan, Y. L., A. Ye, H. Singh, and Y. Hemar. 2007. Effects of biopolymer addition on the dynamic rheology and microstructure of renneted skim milk systems. J. Texture Stud. 38:404-422.

van Vliet, T. 1988. Rheological properties of filled gels. Influence of filler matrix interaction. Colloid Polym. Sci. 266:518-524.

van Vliet, T., H. J. M. van Dijk, P. Zoon, and P. Walstra. 1991. Relation between syneresis and rheological properties of particle gels. Colloid Polym. Sci. 269:620-627.

Zhou, N., and S. J. Mulvaney. 1998. The effect of milk fat, the ratio of casein to water, and temperature on the viscoelastic properties of rennet casein gels. J. Dairy Sci. 81:2561-2571.

Zoon, P., T. van Vliet, and P. Walstra. 1988. Rheological properties of rennet-induced skim milk gels. 2. Effect of temperature. Neth. Milk Dairy J. 42:271-294. 